\title{
Laser Ablative Cutting of Ceramics for Electronics Applications
}

\author{
B. E. Warner \\ E. P. Dragon \\ J. J. Chang \\ N. M. Ceglio
}

March 1, 1996

This is an informal report intended primarily for internal or limited external diatribution. The opinions and conclusions etated are those of the author and may or may not be those of the Laboratory.

Work performed under the auspices of the U.S. Department of Energy by the Lawrence Livermore National Laboratory under Contract W-7405-Eng-18. 


\section{DISCLAIMER}

This document was prepared as an account of work sponsored by an agency of the United States Government. Neither the United States Government nor the University of California nor any of their employees, makes any warranty, express or implied, or assumes any legal liability or responsibility for the accuracy, completeness, or usefulness of any information, apparatus, product, or process disclosed, or represents that its use would not infringe privately owned rights. Reference herein to any specific commercial product, process, or service by trade name, trademark, manufacturer, or otherwise, does not necessarily constitute or imply its endorsement, recommendation, or favoring by the United States Government or the University of California. The views and opinions of authors expressed herein do not necessarily state or reflect those of the United States Government or the University of California, and shall not be used for advertising or product endorsement purposes.

This report has been reproduced directly from the best available copy.

Available to DOE and DOE contractors from the Office of Scientific and Technical Information

P.O. Box 62, Oak Ridge, TN 37831

Prices available from (615) 576-8401, FTS 626-8401

Available to the public from the

National Technical Information Service

U.S. Department of Commerce

5285 Port Royal Rd.,

Springfield, VA 22161 


\title{
Laser Ablative Cutting of Ceramics for Electronics Applications
}

\author{
B. E. Warner, E. P. Dragon, J. J. Chang, and N. M. Ceglio
}

\begin{abstract}
Pulsed, high-beam quality lasers offer unique materials processing characteristics. In processing metals, copper vapor and pulsed Nd:YAG lasers have produced micronscale cuts and holes with submicron heat-affected zones. Since the cost of laser photons is high and average material removal rates can be slow with ablation, high value-added applications are necessary to justify processing costs. Ceramics present a special challenge for manufacturing because of their high hardness, relatively low thermal conductivity, and brittle nature. Surface damage typically limits the strength of a ceramic part to a small fraction of its bulk strength. This work investigates the use of copper vapor and pulsed diode-pumped Nd:YAG lasers to cut precision features in ceramic substrates. Variations in laser wavelength and power, processing speed, ceramic type, and assist gas were investigated with the goal of producing $<100-\mu \mathrm{m}$ wide by $600-\mu \mathrm{m}$ deep cuts through silicon-carbide and alumina/titanium-carbide substrates for potential use in electronics. Silicon-carbide bars $250-\mu \mathrm{m}$ wide by $600-\mu \mathrm{m}$ high by $2.5-\mathrm{cm}$ long were laser cut from substrates without fracture.
\end{abstract}

\section{Introduction}

Use of ceramics in industry is not typically limited by their material properties or cost, but by the high cost of finished part manufacturing. Choices of machining tools for processing ceramics, such as alumina, silicon-carbide, or alumina/titanium-carbide are very limited. For example, present manufacturing methods for magnetic head sliders require diamond saw cutting followed by multiple grinding and polishing steps. These wet processes, coupled with the fragility of the ceramic substrates, contribute to a relatively low yield for these components. As feature sizes become smaller on electronic components, these mechanical processing methods can further limit yield, placing higher cost pressure on the manufacturing process.

The limitations of conventional ceramics manufacturing and the pursuit of smaller feature size present a potential economic opportunity for lasers. The use of lasers increased in ceramics processing, and its application is not limited to micromachining. ${ }^{1}$ 
To capitalize on this opportunity, the laser must be able to do the following: (1) cut through various ceramic substrates with a kerf width of less than $\sim 100 \mu \mathrm{m}$, (2) cut without inducing significant surface damage, and (3) cut with little bulk heating so as to avoid thermal stress fracture of the part at acceptable cutting speeds.

The present work was undertaken to apply knowledge gained from metals processing with copper vapor and pulsed Nd:YAG lasers to the processing of advanced ceramics. ${ }^{2}$ In processing of metals, these lasers show very good cut properties at moderate cut rates. They are: the high-aspect ratio (20 to 50:1) cuts with 25-50- $\mu \mathrm{m}$ kerf widths, micron-scale heat affected zones, and the ability to cut refractory metals. Metals as opposed to ceramics are very forgiving with respect to thermally-induced stress. Ceramics fracture under high tensile stress. In addition, surface cracks often limit the part's strength and lifetime because they can propagate into the bulk. Laser ablative cutting has significant promise for ceramics if adequate cut rates and controllable material removal per incident pulse can be achieved without thermal fracture and without significant surface damage.

\section{Method}

\section{Lasers}

There were two pulsed lasers utilized in this study: a copper vapor laser and a diode-pumped Nd:YAG laser. Each was designed and assembled at Lawrence Livermore National Laboratory (LLNL). The copper vapor laser generates 50 -ns pulses at $\sim 4500$ pulses per second at wavelengths of 510 and $578 \mathrm{~nm}$. Typical power on the workpiece was varied from a few to 200 watts. Beam quality for this laser can approach the diffraction limit, but during these tests, beam quality was approximately three times the diffraction limit. ${ }^{3}$ Beam polarization was random. An F10 optical system was typically used to focus the beam on the ceramic substrate. With the copper vapor laser, peak intensities on the part ranged from $10^{8}$ to $5 \times 10^{10} \mathrm{~W} / \mathrm{cm}^{2}$.

The diode-pumped Nd:YAG laser has a side-pumped rod architecture. ${ }^{4}$ It was operated for this study at $\sim 30 \mathrm{~W}$ at $1.06-\mu \mathrm{m}$ wavelength, 700 pulses per second, and $200 \mu$ s pulse length. By Q-switching and adding limiting apertures in the resonator, it produces $\sim 10 \mathrm{~W}$, with two-times diffraction-limited beam quality. The pulse length under these Q-switching conditions was $50 \mathrm{~ns}$. As with the copper vapor laser, an F10 optical system was used to focus the beam on the ceramic substrate. Beam polarization was selected to be either random or linear. The Nd:YAG laser was utilized in both the long pulse and Q-switched configurations for this study.

\section{Materials}

This study was limited to two ceramic substrate materials: alumina/titaniumcarbide and silicon-carbide. The $\mathrm{Al}_{2} \mathrm{O}_{3} / \mathrm{TiC}$ is the current choice of magnetic head 
slider manufacturers. $\mathrm{SiC}$ represents a potentially new substrate material for this application. Properties for chemical vapor deposition (CVD)-grown SiC used in this study are listed in Table 1. Notably, it has a thermal conductivity higher than aluminum, and it can be polished to subnanometer smoothness. SiC, however, is fairly brittle and very hard. Mechanical manufacturing methods require diamond processing. On the contrary, it is a good candidate for laser processing because of its high thermal conductivity.

High cutting speed and efficiency is important to successful ceramic processing with lasers. The application of short-pulsed lasers in ceramic cutting are not limited by available laser power, but by its ability to cut the ceramics fast enough for practical application with low enough beam power to avoid inducing thermal stress fracture of the substrate. Early, low-finesse tests with relatively high beam powers resulted in fractured ceramics and occasional ejected debris. Consequently, two investigations were emphasized: (1) methods to increase cutting efficiency and (2) methods to avoid localized heating and fracture.

Assist gases received a thorough examination as a method of increasing cutting efficiency. Conventional laser cutting with millisecond or continuous wave lasers utilize assist gases to great advantage. ${ }^{5}$ The assist gas can react with the substrate to add chemical energy to the cutting process. It can also provide a method to blow liquid

Table 1. Properties of CVD Silicon Carbide

\begin{tabular}{|c|c|}
\hline Property & $\begin{array}{l}\text { CVD }^{+} \text {Silicon } \\
\text { Carbide }^{\mathrm{TM}}\end{array}$ \\
\hline $\begin{array}{l}\text { Density } \\
\left(\mathrm{g} / \mathrm{cm}^{3}\right)\end{array}$ & 3.21 \\
\hline $\begin{array}{l}\text { Elastic modulus } \\
(\mathrm{GPa})\end{array}$ & 466 \\
\hline $\begin{array}{l}\text { Yield strength } \\
(\mathrm{MPa})\end{array}$ & 470 \\
\hline $\begin{array}{l}\text { Thermal conductivity } \\
\text { (W/mk) }\end{array}$ & 250 \\
\hline $\begin{array}{l}\text { Heat capacity } \\
\mathrm{J} / \mathrm{kg} \mathrm{K}\end{array}$ & 733 \\
\hline $\begin{array}{l}\text { Thermal expansion } \\
\text { coefficient (ppm/k) }\end{array}$ & 2.2 \\
\hline $\begin{array}{l}\text { Knoop hardness } \\
\left(\mathrm{kg} / \mathrm{mm}^{2}\right)\end{array}$ & 2500 \\
\hline $\begin{array}{l}\text { Polishability } \\
\text { ( } \AA \text { RMS) }\end{array}$ & $<3$ \\
\hline
\end{tabular}


away from the active cut zone. These effects are not so dramatic for short pulsed lasers, since pulsed illumination creates a vapor plume with as much as 1000 ATM pressure.6,7 In addition, liquid layers are calculated to be only microns thick. ${ }^{7}$ The rapidly expanding vapor plume sweeps the assist gas from the processing area. Despite this, factors of $\sim 2$ increase in ablative cutting rates have been observed in using oxygen to cut steel.

Oxygen and nitrogen were first tested as assist gases for $\mathrm{SiC}$. It was found empirically that nitrogen increased the cutting rate ( $25 \%$ effect) for the long pulse, $200 \mu \mathrm{s}, \mathrm{Nd}: Y A G$ laser. For the shorter pulsed lasers, a nitrogen purge helped clean up the cut, but did not appear to increase the cutting speed measurably. Most of the data taken in this study, except as noted, utilized a nitrogen purge. Oxygen was found to slow down the cutting rates for the lasers used in this study. Subsequently, the assist gases were considered analytically by calculating reaction rates with $\mathrm{SiC}$ and by product species as a function of temperature. Under all reasonable conditions, oxygen as an assist gas with $\mathrm{SiC}$ produced $\mathrm{SiO}_{2}$, known to be difficult to ablate with visible lasers. This analytical search yielded only one gas that appears feasible to increase $\mathrm{SiC}$ cutting rates, fluorine.

Others have been successful in using halogen or gaseous halides as the carrier gas for delivering halogen to the cut zone. ${ }^{8} \mathrm{SF}_{6}$ was tested in this work as an assist gas. It was not delivered through a nozzle. Instead, a sealed stainless steel vessel was used to contain the $\mathrm{SiC}$ substrate and the $\mathrm{SF}_{6}$ gas. The laser was incident on the substrate through a window. This method is not as effective in delivering the gas to the cut zone, but was a compromise to test the assist gas effect while addressing safety concerns at a reasonable cost. Results of these cutting tests will be described below.

\section{Workpiece Movement}

There are three time constants relevant to ablative cutting under present conditions. The first is the laser beam pulse length $(50 \mathrm{~ns})$. During this time, the temperature of the illuminated surface rapidly (in ns) increases to as much as $10^{5}$ degrees (all temperatures in Celsius), which causes vapor ejection and residual heat left at the illumination site. ${ }^{9}$ The second time constant is the time to the next pulse, in this study either 0.2 or $1.4 \mathrm{~ms}$. The third time constant is the equilibration time constant for the part. This time can be estimated by:

$$
\tau \sim \rho c \Delta x^{2} / D,
$$

where $\rho, c, \Delta x$, and $D$ are density, heat capacity, distance to heat sink, and thermal conductivity, respectively. Using the substrate thickness and other constants from Table 1 , this time constant is $\sim 4 \mathrm{~ms}$. Since thermal equilibration of the substrate requires several time constants and the pulse to pulse time is much shorter, workpiece movement is important in determining whether residual heat at illumination sites builds up from pulse to pulse. Illumination sites that are within $\sim \mathrm{mm}$ will build temperatures and gradients. The closer they are together, the higher the temperature and gradient. 
Delivery of the laser to the workpiece is, therefore, crucial in controlling the temperature gradients in the substrate and in controlling the induced stresses. Bounding calculations were made for this work using a three-dimensional heat transfer and mechanics code.10,11 In a thermally ideal case, a constant heat flux of $100 \mathrm{~W}$ was uniformly spread over a $100-\mu \mathrm{m}$-by 10 -cm stripe on a $600-\mu \mathrm{m}$-thick $\mathrm{SiC}$ substrate. Heat loss was assumed to be through the substrate to a water cooled base plate, with appropriate thermal diffusivity. This steady-state calculation results in only a $6^{\circ}$ temperature gradient over the entire substrate. The high thermal conductivity of SiC and the relatively large $0.1 \mathrm{~cm}^{2}$ area of illumination cause this small thermal gradient and negligible induced stress. This indicates that the ideal beam delivery would illuminate the area to be cut simultaneously and uniformly. Unfortunately, an optical system that can take a round, .3-cm diam. Nd:YAG laser beam or a 4-cm diam. copper vapor laser beam and efficiently transform it into a uniform intensity $100-\mu \mathrm{m}$ by $10-\mathrm{cm}$ linear beam has not yet been developed.

The other bounding calculation is a near stationary 100-W illumination of a 100-by $100-\mu \mathrm{m}$ spot on the substrate. This illumination has the same power incident on a thousand times smaller area than the above case. The results were dramatically different. Calculated thermal gradients are over $1000^{\circ}$ with tensile and compressive stresses of the order of $2000 \mathrm{GPa}\left(\sim 3 \times 10^{5} \mathrm{psi}\right)$, well over the yield stress of the material. While the details of this model are not reliable at these temperatures because phase change and materials properties are not treated, it is easy to conclude that a near stationary beam at this small spot size is likely to fracture the substrate or cause significant local damage.

The third case calculated included workpiece movement. In this case the 100-W heat flux was incident on a 100 - by $500-\mu \mathrm{m}$ spot. The asymmetric spot was used to simulate partial cylindrical focusing of the laser beam. The $500-\mu \mathrm{m}$ dimension was along the cut path. In the calculation this spot was swept over the substrate at $25 \mathrm{~cm} / \mathrm{s}$. (At the copper laser pulse repetition rate, this sweep rate would cause a $90 \%$ spatial pulse overlap. At the Nd:YAG pulse repetition rate, this sweep rate would cause a $30 \%$ pulse overlap. This calculation still does not account for the pulsed nature of our laser in that the heat flux is continuous. Since the pulses in this calculation are overlapped, it gives us reasonable confidence in the results. Better treatment would put discrete heat sources along the sweep path at discrete times to simulate the pulsed nature of our lasers.)

The calculation further assumed that the cut had progressed $60 \%$ of the way through the substrate. Figure 1(a) shows the calculational grid for this geometry. The heat flux was placed on the web surface between the two substrate sides. Under these calculational conditions, the maximum temperature reached on the substrate was $750^{\circ}$, with a $600^{\circ}$ gradient over the substrate thickness [Fig. 1(b)]. Corresponding calculated maximum tensile stress was $255 \mathrm{GPa}(37,000 \mathrm{psi})$ or about half of the yield stress of the material. Clearly, by calculation, these conditions are still risky because they lead to substrate fracture during processing. Our work indicate that successful cutting should require a combination of the following: residual heat fluxes lower than $100 \mathrm{~W}$, 
illumination areas of greater than $100 \mu \mathrm{m}$ by $500 \mu \mathrm{m}$, or sweep rates greater than $25 \mathrm{~cm} / \mathrm{s}$.

As just described, the beam power and movement on the ceramic substrate determines the thermal loading and resultant stress in the ceramic during processing. High stress can lead to fracture during cutting, an undesirable event. A series of cutting tests were performed. This study was initiated utilizing a Lumonics processing table (model 520), customized for high travel speed. It is capable of $25 \mathrm{~cm} / \mathrm{s}$ travel, but because of table vibration at these speeds, it was operated at $3 \mathrm{~cm} / \mathrm{s}$. Below, we will describe the fracture that normally occurs when the cut reached $50-70 \%$ of the substrate depth at this table speed. Useful data on efficiency of material removal was obtained up until the point of fracture.

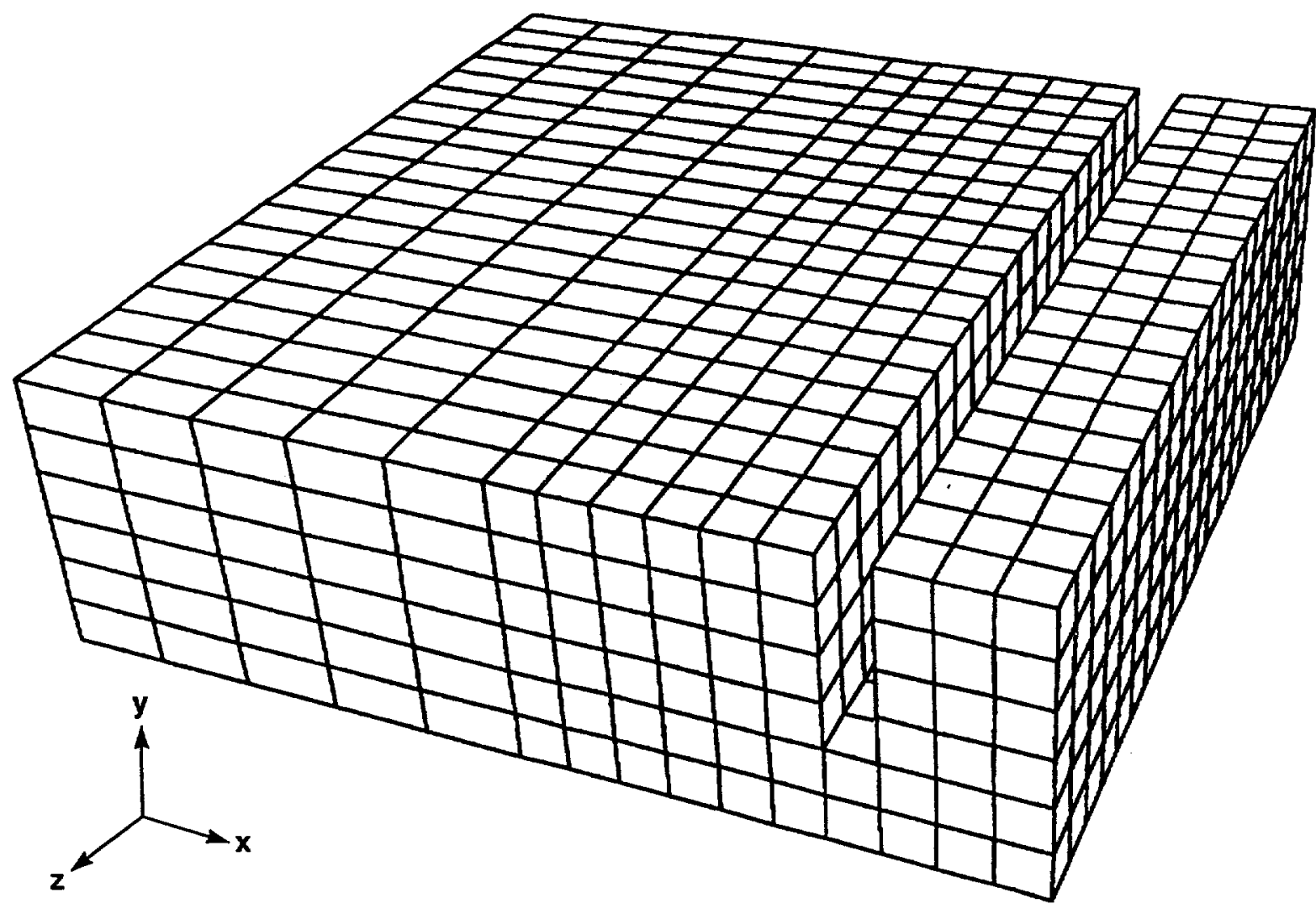

1.5.0396.0598pb01

Figure 1a. Calculation grid used to model partially cut substrate. 
Fringe levels

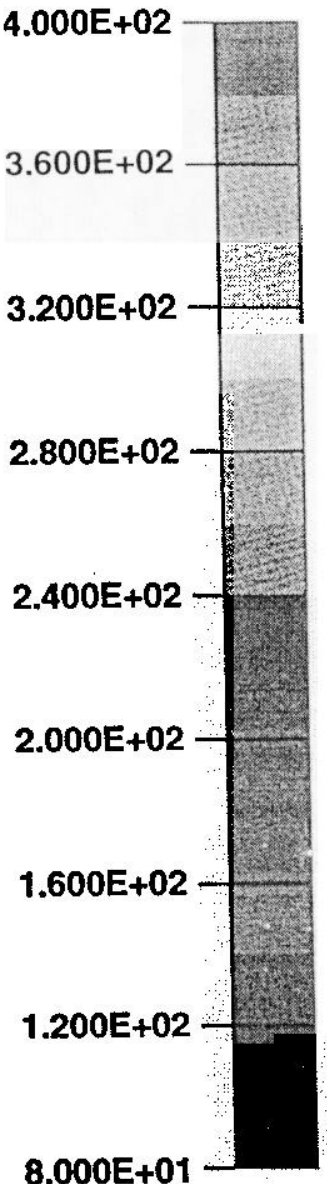

$1.5 .0396 .0605 \mathrm{pbo}$

Figure 1b. Calculated thermal profile for laser illuminated SiC substrate. Thermal gradients are pronounced in the illuminated area, with a peak temperature of $750^{\circ} \mathrm{C}$ at the center of the orange zone.

The desire for high travel speed of the workpiece and a technique consistent with micron-scale accuracy guided a workpiece movement design that sweeps the laser beam rather than the substrate. A galvonometric-driven mirror and flat field optical system were specified and purchased. This system was utilized to sweep the laser beam across a stationary substrate. This allowed several orders of magnitude faster beam/ substrate movement of up to $500 \mathrm{~cm} / \mathrm{sec}$. Figure 2 is a schematic layout of this arrangement. A beam with a nominal 40 -by $40-\mu \mathrm{m}$ spot (copper vapor laser) or 80 -by $80-\mu \mathrm{m}$ spot (Nd:YAG) was typically swept repetitively across a $2.5-\mathrm{cm}$ substrate at 10 to $100 \mathrm{hz}$. By using this hardware, full depth cutting of the $\mathrm{SiC}$ and $\mathrm{Al}_{2} \mathrm{O}_{3} / \mathrm{TiC}$ substrates was accomplished without fracture.

Cutting speeds and efficiencies were measured with the swept beam. The sinusoidal drive on the galvo-mirror results in more pulses being applied to the ends of the sweep during the turning around of the beam position for fixed laser pulse interval. Consequently, the ends of the substrates were cut through before the center. 


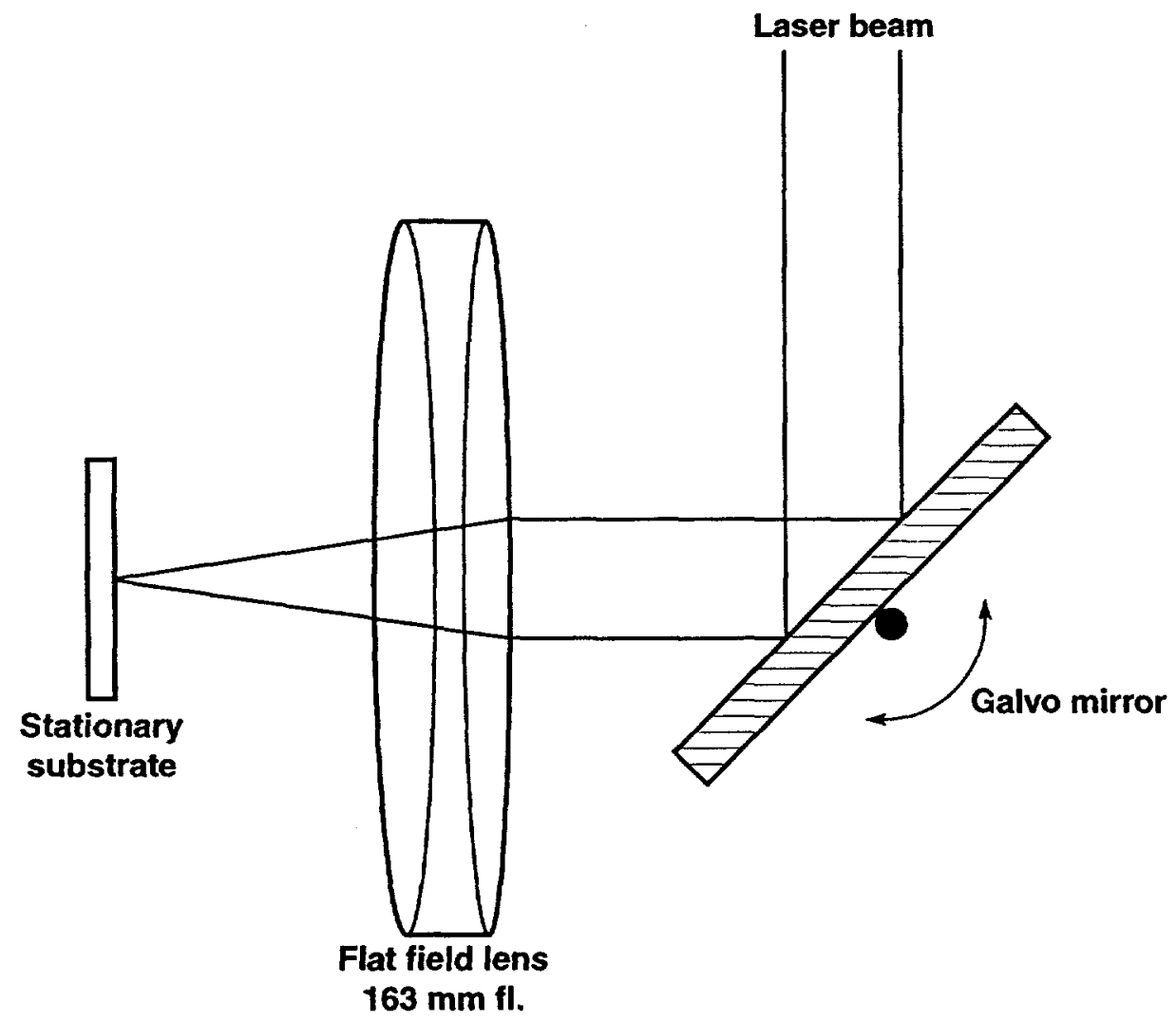

1.5.0396.0604p601

Figure 2. Schematic layout of beam sweep hardware.

Measurements of cutting rates accounted for this effect. Note that the pulsing of the lasers and the sweeping of the galvo-mirror were asynchronous. Cuts of length longer than $2.5 \mathrm{~cm}$ are possible with this arrangement, limited by the aperture of the optical delivery system (galvo-mirror and flat field lens).

\section{Results}

\section{Copper Vapor Laser Cutting - $3 \mathrm{~cm} / \mathrm{s}$ workpiece movement}

Cutting tests with the copper vapor laser were carried out with two-part movement systems: one with $3-\mathrm{cm} / \mathrm{s}$ workpiece movement and the other with nominally $>50-\mathrm{cm} / \mathrm{s}$ beam sweep. For each of these, the small beam spot of the copper laser $(40 \mu \mathrm{m})$ and the linear reciprocating motion produced $50-\mu \mathrm{m}$ kerf widths at the top that tapered narrower as the cut progressed down into the substrate. Cuts were measured for kerf width and depth along with cut length during a specific time interval. A figure of merit utilized during this study was the number of cubic $\mathrm{mm}$ of ceramic removed by a kilojoule of laser energy on the substrate $\left(\mathrm{mm}^{3} / \mathrm{kJ}\right)$. This figure of merit scales the 
laser power necessary to cut a specific distance in a given amount of time, and it helps determine the heat load and stress for this processing requirement. For instance, a ten times higher removal rate per kilojoule of laser energy allows a smaller laser to be employed for a given cutting rate, and it lowers thermal loads during that cutting.

The first set of copper laser cutting data was taken at copper laser power levels over $100 \mathrm{~W}$. In these tests, 0.6- and 0.8-mm thick substrates were used for $\mathrm{SiC}$ and $\mathrm{Al}_{2} \mathrm{O}_{3} / \mathrm{TiC}$, respectively. The data were taken using the slower part movement speed, background gas pressure varied from atmospheric pressure to as low as a few torr. At this relatively high copper laser power and low speed part movement fracture occurred near the end of the cut. An example is displayed in Fig. 3. In this figure, a cross section of the cut has been photographed. The top $80 \%$ of the substrate has been cut with the laser while the lower $20 \%$ fractured, as indicated by the different surface texture. The texture at the top of the cut is determined by the geometric overlap of the copper laser pulses. The average roughness there is a few microns. The middle third of the cut has an order of magnitude higher roughness because of wander in the penetration of the laser as the aspect ratio of the cut got to $\sim 6: 1$. The lower part of the cross section has very large deviation in edge position because of the fracture of the substrate.

Figure 4 shows cutting efficiency $\left(\mathrm{mm}^{3} / \mathrm{kJ}\right)$ for this initial test. There are four curves represented. Two for ambient air and two for $\mathrm{SF}_{6}$ background gas. For each substrate at all pressures, $\mathrm{SF}_{6}$ background gas increases the cutting efficiency by about a factor of two. In addition, each of the substrates in this test was cut with about the same average cutting efficiency, $\sim 0.25 \mathrm{~mm}^{3} / \mathrm{kJ}$ in air. Notice that the cutting efficiency of the $\mathrm{Al}_{2} \mathrm{O}_{3} / \mathrm{TiC}$ increases at pressures below 100 torr. We think that the ablation plume propagates more rapidly up and out of the kerf with lower background gas pressure. It is curious that this is not observed for $\mathrm{SiC}$.

As an example, the data curve in Fig. 3 will be used to calculate a cutting time for a representative substrate. At the highest cutting efficiency under the conditions represented in that figure $\left(0.5 \mathrm{~mm}^{3} / \mathrm{kJ}\right)$, a $100-W$ (i.e., $100 \mathrm{~J} / \mathrm{s}$ ) copper laser cuts a $2.5-\mathrm{cm}$ long by $0.6-\mathrm{mm}$-thick substrate through in 9 seconds, with a $50-\mu \mathrm{m}$ kerf that tapers to $\sim 10 \mu \mathrm{m}$ near the bottom. In addition, because of stresses induced during the cutting, there is likely to be a fracture.

\section{Copper Vapor Laser Cutting - $400 \mathrm{~cm} / \mathrm{s}$ beam sweep}

As described above, the fast beam sweep was used to spread the heat load across the substrate during cutting. Scan rates of $10-80 \mathrm{hz}$ ( 50 to $400 \mathrm{~cm} / \mathrm{sec}$ average velocity) over a $2.5-\mathrm{cm}$ distance produced very similar cutting characteristics. Data discussed in this section were all taken with a 80-hz sweep. Utilizing this sweep method and the nominal copper laser beam delivery, this laser was able to cut off ceramic bars of each substrate measuring $300-\mu \mathrm{m}$ wide by $600-\mu \mathrm{m}$ high by $2.5-\mathrm{cm}$ long (or $800-\mu \mathrm{m}$ high in the case of $\mathrm{Al}_{2} \mathrm{O}_{3} / \mathrm{TiC}$ ). The kerf width for these cuts were the nominal $50-\mu \mathrm{m}$ wide, tapering to roughly $10 \mu \mathrm{m}$ at the bottom of the cut (representing a 12:1 cut aspect ratio). 


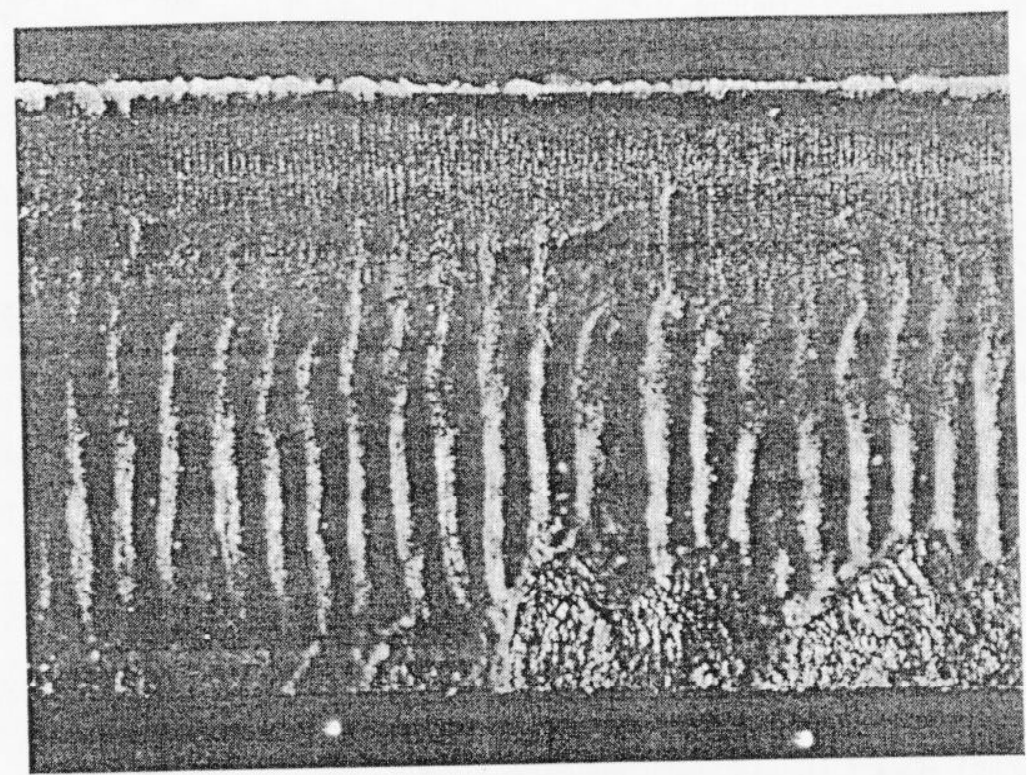

$0606 \mathrm{pb0}$

Figure 3. Photograph of cut surface resulting from $100 \mathrm{~W}$ CVL beam and $3 \mu \mathrm{m} / \mathrm{sec}$ substrate travel speed.

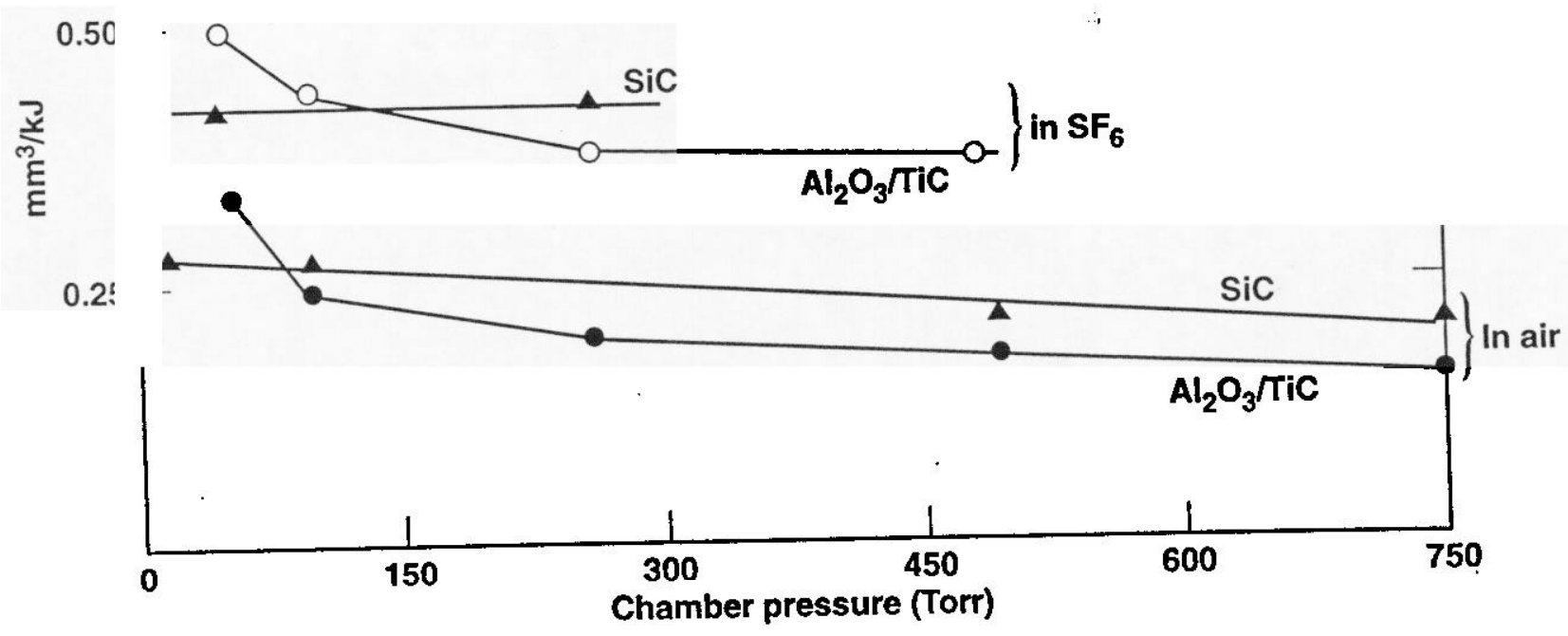

$1.5 .0396 .0599 \mathrm{pb0} 1$

Figure 4. Cutting efficiency $\left(\mathrm{mm}^{3} / \mathrm{kJ}\right)$ as a function of chamber pressure for air and $\mathrm{SF}_{6}$. 
This was accomplished with relatively low beam powers (up to $7 \mathrm{~W}$ total). Higher beam powers spread over the $2.5-\mathrm{cm}$ cut length caused fracture of the substrate before the cut was complete. This fracture limit was consistent for all sweep frequencies over $10 \mathrm{hz}$. At slower sweep rate, fracture occurred before cut through. (At 80-hz sweep rate, the individual laser illumination spots are separated on the average by $800 \mu \mathrm{m}$.)

An example of this precision cutting is represented in Fig. 5 . It is a photograph of a $2.5-\mathrm{cm}$-diam $\mathrm{SiC}$ substrate that has 27 parallel cuts, $1.3-\mathrm{cm}$ long through the $600-\mu \mathrm{m}$ thickness. The cuts are spaced by $300 \mu \mathrm{m}$ each. Even though these segments were constrained because of the ends, none of the segments fractured during cutting. There is some cutting debris left in a few of the cuts.

In cutting these substrates we observed that the cutting speed slowed down considerably during the cut. We think this is caused by the aspect ratio of the cut gettirig higher as the cut gets deeper, causing a higher deposition of ablated material back on the side wall of the cut. Figure 6 shows the cutting efficiency as a function of aspect ratio for both types of ceramic substrates. The data were taken by cutting for a specific period of time, measuring the amount of material removed, and dividing by the laser energy expended. Notice the factor of 3 decrease in average efficiency between relatively low aspect ratios and ones over 12 . As measured and implicit in the data in Fig. 6 , the energy to cut the $\mathrm{SiC}$ substrate down to $500-\mu \mathrm{m}$ depth (aspect ratio of 10 ) is equal to the energy to cut from 500 to $600 \mu \mathrm{m}$ (to an aspect ratio of 12). This indicates

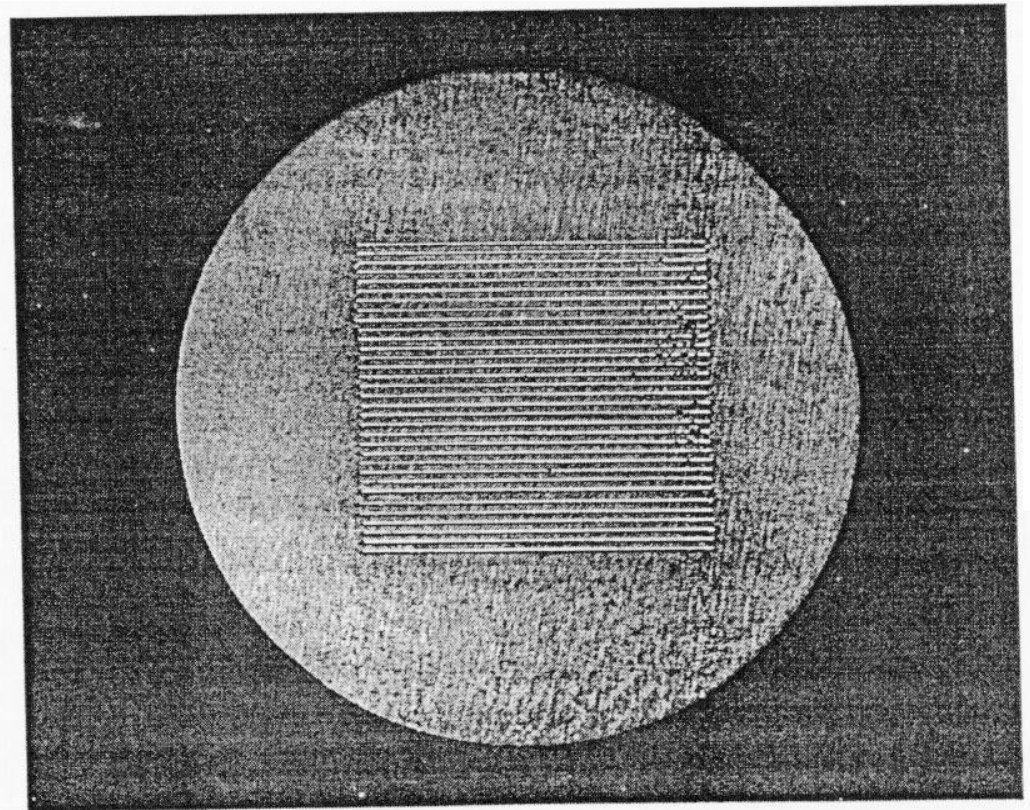

1.5.0396.0607pb01

Figure 5. Photograph of parallel $50 \mu \mathrm{m}$ wide copper vapor laser cuts in $600 \mu \mathrm{m}$ thick SiC. 


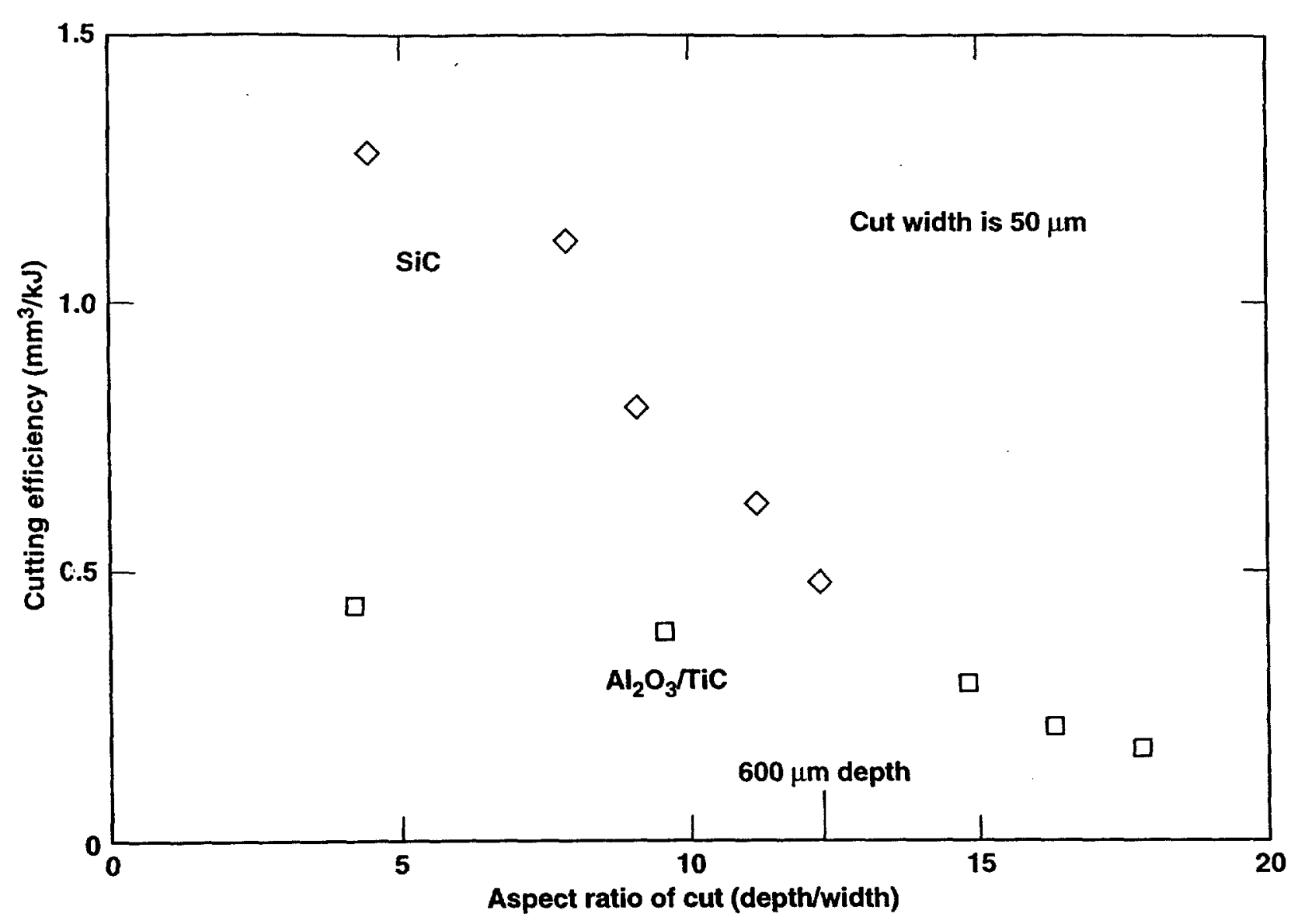

1.5.0396.0601pb01

Figure 6. Copper laser cutting efficiency as a function of cut aspect ratio.

that there is significant leverage in cutting these substrates from both sides, thereby reducing the required aspect ratio by a factor of 2 . The total energy expended on twosided cutting of these substrates could be as low as $40 \%$ of that expended to cut one side, primarily due to the reduced aspect ratio of the cuts.

\section{Nd:YAG Laser Cutting of SiC}

For the initial tests, the Nd:YAG laser was not Q-switched, resulting in 250- $\mu \mathrm{m}$ pulses. It operated with $13 \mathrm{~W}$ on the workpiece. All other laser parameters were as described above. The scanning beam system was utilized to sweep the beam at $10 \mathrm{hz}$ ( $50 \mathrm{~cm} / \mathrm{s}$ average speed). Under these conditions, the Nd:YAG laser did not penetrate the $\mathrm{SiC}$ substrate. Between 3 and 5 minutes of exposure, the cut depth remained at $\sim 230 \mu \mathrm{m}$. These long pulses and low peak power illumination $\left(\sim 1.5 \times 10^{6} \mathrm{~W} / \mathrm{cm}^{2}\right)$ appear to be unable to ablate the material out of the illumination sites at an aspect ratio of 2.5. (This longer pulse laser is successful with key hole cutting.)

The Nd:YAG laser was subsequently Q-switched to produce 50 -ns pulses at an average power of $6 \mathrm{~W}$. For these tests, the beam sweep was operated at $10 \mathrm{hz}(50 \mathrm{~cm} / \mathrm{s})$. 
The beam spot on the part was $80 \mu \mathrm{m}$, producing a cut that was $\sim 100 \mu \mathrm{m}$ at the top, tapering to tens of microns at the bottom. This cut represents a smaller aspect ratio than the copper laser cuts because of the twice bigger kerf width for a fixed depth. With an unpolarized laser beam, cutting efficiencies were very similar to those of the copper vapor laser (Fig.7). Near the surface of the cut, $1.25 \mathrm{~mm}^{3} / \mathrm{kJ}$ was removed by the Q-switched Nd:YAG laser. This efficiency decreased significantly as the cut progressed. Since the kerf width was twice as large as that with the copper vapor laser, energy requirements and time to penetrate the substrate was also twice as large as with the copper laser. The Nd:YAG laser was utilized to cut off ceramic bars without fracture of approximately the same size as with the copper vapor laser. The cut edge finish was somewhat more coarse because of the larger spot size.

Polarization control of the laser beam is sometimes used to optimize cutting parameters. The Q-switched Nd:YAG laser was operated in a linear polarized manner and tested for cutting efficiency; it was compared to the unpolarized results described above. These tests are summarized on Fig. 7. We found that with a beam polarized perpendicular to the cut direction, the cutting efficiency doubled for low aspect ratios and tripled for high aspect ratios. We believe that with the $1.06-\mu \mathrm{m}$ wavelength polarized normal to the side wall, high-angle reflection is reduced, which increases the coupling efficiency to the $\mathrm{SiC}$. This increased coupling also increases the kerf width by about $25 \%$ over the unpolarized beam, resulting at a smaller aspect ratio (4.7 instead of 6) at full penetration of the substrate. With a beam polarized along the cut direction, the cutting efficiency dropped by a factor of 2 , as indicated on Fig. 7. From this data it appears that the polarization component normal to the side wall of an unpolarized beam contributes to the dominant work in cutting through the substrate.

\section{Summary}

Laser ablative cutting of ceramic substrates has been demonstrated at moderate rates with 5 to $10 \mathrm{~W}$, near diffraction-limited copper vapor and diode-pumped Nd:YAG lasers. In this work, these lasers have demonstrated kerf widths less than $100 \mu \mathrm{m}$, through 600 and $800 \mu \mathrm{m}$ thick substrates of $\mathrm{SiC}$ and $\mathrm{Al}_{2} \mathrm{O}_{3} / \mathrm{TiC}$. Cutting rates slow down considerably as the cut progresses to high aspect ratios. Material removal efficiencies as high as $2.3 \mathrm{~mm}^{3} / \mathrm{kJ}$ were demonstrated on $\mathrm{SiC}$, dropping to $10 \%$ of that value at high aspect ratios. Beam scan velocities of greater than $25 \mathrm{~cm} / \mathrm{s}$ were required to spread the thermal load on the substrate in order to avoid fracture. This was accomplished using a galvo driven mirror and flat-field lens. Bars of dimensions $300 \times 600 \mu \mathrm{m}$ by $2.5 \mathrm{~cm}$ were laser cut from substrates without fracture. More progress in ablative cutting of ceramics may result from testing and utilizing other pulse formats that could have higher cutting efficiency. Higher cutting efficiency benefits ceramic cutting in two ways: lower laser requirements and less thermal load resulting in less chance for fracture. 


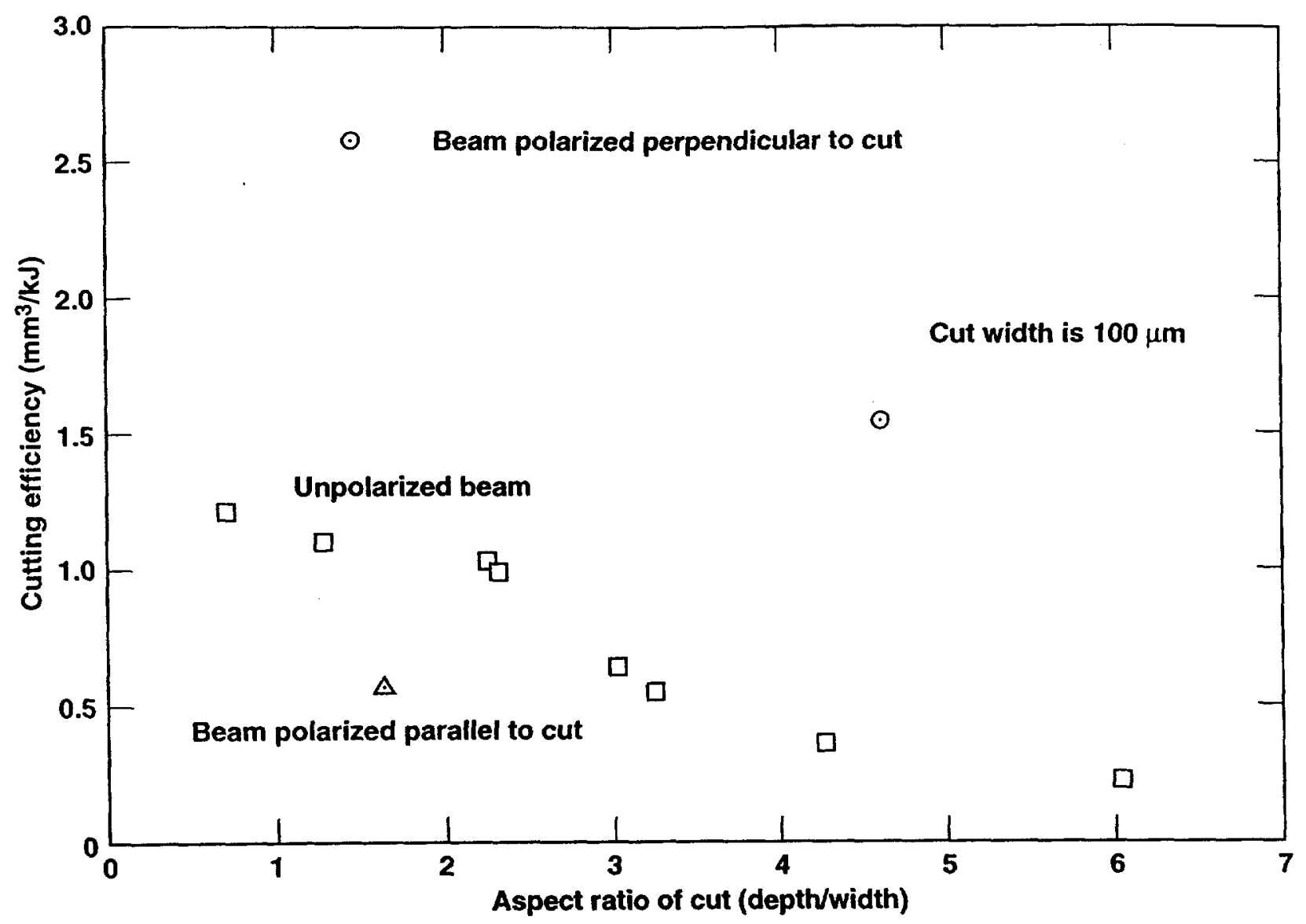

1.5.0396.0600pb01

Figure 7. YAG laser cutting efficiency of $\mathrm{SiC}$ as a function of cut aspect ratio.

\section{Acknowledgements}

The authors would like to acknowledge key contributions from the following individuals (all of LLNL): Glen Huete for laser cutting support, Phil Brady for themal/stress analysis, Lloyd Hackel and Mark Herman for DPSSL support, Bill McLean, II for chemical reaction analysis, and Martha Maser for clerical support. In addition, the authors would like to thank Dr. Hemant Desai at Morton International for information and advice on CVD Silicon Carbide. 


\section{References}

1. Ogata, K., Miyanagi, N., Suzuki, K., Shimomura, Y, “Ceramics Cutting with pulsed Nd:YAG laser," LIA 71261 (1991). Published by Laser Inst. of America, Toledo, $\mathrm{OH}, \mathrm{USA}$

2. Toenshoff, H.K., Hesse, D., Mommsen, J., "Micromachining Using Excimer Lasers," CIRP Annals 42, 247 (1993).

3. Meiners, E, Kessler, A., Dausinger, F., Hugel. H, "Approaches in Modeling of Evaporative and Melt Removal Processes in Micromachining," DGM Infromationsgesellschaft mbh, Adenaurallee 21, D-6370 Oberursel 1, Germany (1992).

4. Tam, S. C., Williams, R., Yang, L. J.; Jana, S.,Lim, L., Lau, M.W.S., "A Review of the Laser Processing of Aircraft Components," J. Mat. Proc. Technol. 23, 177 (1990).

5. Chang. J. "Precision Micro Drilling with Copper Vapor Lasers" Lawrence Livermore National Laboratory, Livermore, CA, UCRL-117092 (1994).

6. Chang, J., Warner, B. "Properties of High Radiance Laser-Material Interaction for Manufacturing," Lawrence Livermore National Laboratory, Livermore, CA, UCRL119698 (1995).

7. Boley, D., Early, J., "Computational Model of Drilling with High Radiance Pulsed Lasers" Lawrence Livermore National Laboratory, Calif., UCRL-117078 Rev. 1 (1994).

8. Boulmer, J., Budin, J-P., Bourguignon, B., Debarre, D., and Desmur., A., "Laser Ablation of Electronic Materials," Forgarassy, E., and Lazare, S. (eds.) Elsevier Science Publishers (1992).

9. Herman, M., Honig, J., Hachel L., "High Average Power Solid-State Laser for Extreme Ultraviolet Lithography" OSA Proceedings on Extreme Ultraviolet Lithography, 1994 Vol. 23., Fritz Zernike and David T. Attwood (eds.) 1995 OSA.

10. William McLean II, "Private Communication," LLNL (1995). Based on results from the code Otokumpu HSC Chemistry for Windows, v. 2.0, May 31, 1994 by A. Roine, Otokumpu Research, Oy, Pori, Finland.

11. Phil Brady, Lawrence Livermore National Laboratory, Calif., private communications (1995). 


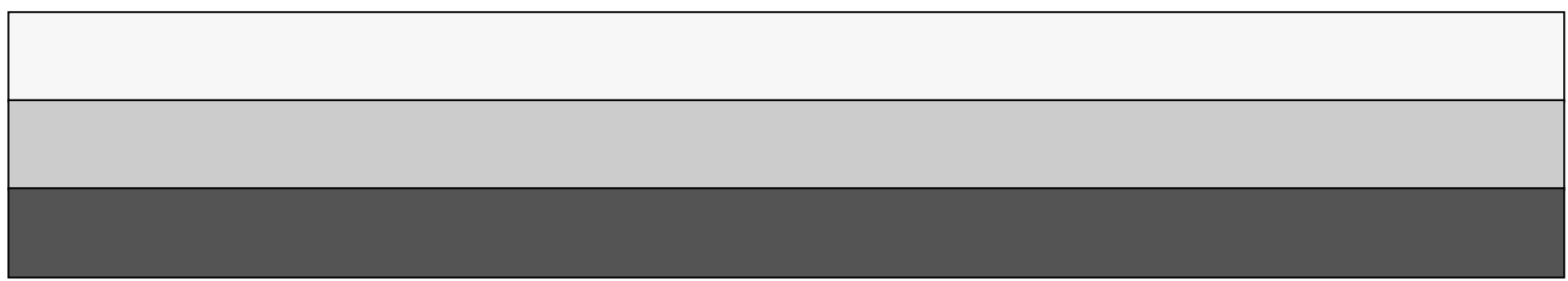

